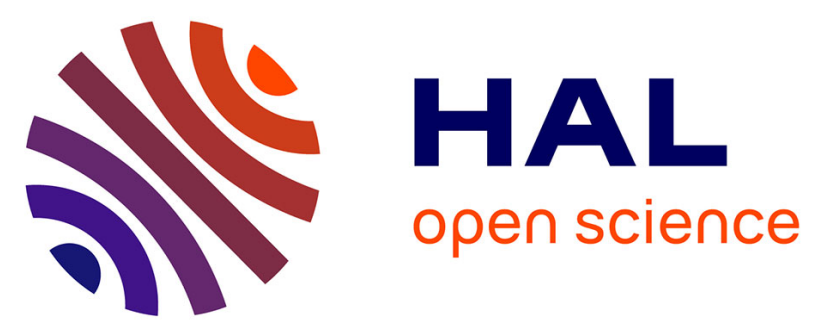

\title{
Development of a Modeling Architecture Incorporating the Industry 4.0 View for a Company in the Gas Sector
}

Nikolaos A. Panayiotou, Konstantinos E. Stergiou, Vasileios P. Stavrou

\section{To cite this version:}

Nikolaos A. Panayiotou, Konstantinos E. Stergiou, Vasileios P. Stavrou. Development of a Modeling Architecture Incorporating the Industry 4.0 View for a Company in the Gas Sector. IFIP International Conference on Advances in Production Management Systems (APMS), Sep 2019, Austin, TX, United States. pp.397-404, 10.1007/978-3-030-29996-5_46. hal-02460510

\section{HAL Id: hal-02460510 https://hal.inria.fr/hal-02460510}

Submitted on 30 Jan 2020

HAL is a multi-disciplinary open access archive for the deposit and dissemination of scientific research documents, whether they are published or not. The documents may come from teaching and research institutions in France or abroad, or from public or private research centers.
L'archive ouverte pluridisciplinaire $\mathbf{H A L}$, est destinée au dépôt et à la diffusion de documents scientifiques de niveau recherche, publiés ou non, émanant des établissements d'enseignement et de recherche français ou étrangers, des laboratoires publics ou privés. 


\title{
Development of a Modeling Architecture Incorporating the Industry 4.0 View for a Company in the Gas Sector
}

\author{
Nikolaos A. Panayiotou ${ }^{1}$, Konstantinos E. Stergiou ${ }^{1}$ and Vasileios P. Stavrou ${ }^{1}$ \\ ${ }^{1}$ National Technical University of Athens, Zografos Campus 15780, Athens, Greece
}

\begin{abstract}
Industry 4.0 is a fast growing concept which has started to gain ground over the last few years and strives to achieve a higher and more efficient production rate through the usage of automations. This concept is directly correlated with Business Process Management because its implementation concerns the improvement of business processes. Business Process Modeling is a tool of Business Process Management which can depict the processes of an organization in order to be elaborated and improved. For that reason models are widely used for the better understanding of processes and as a first step of new concepts insertion, such as Industry 4.0, in an organization. Hence, a comprehensive framework of a modeling architecture is essential for a company which desires the transition to new concepts according to its needs, its processes and its structure. In this paper, a complete architecture which proposed in a company activating in gas industry is presented including the appropriate models for the recording of business processes and how Industry 4.0 principles could be incorporated to them.
\end{abstract}

Keywords: Industry 4.0, Modeling Architecture, Gas Sector.

\section{Introduction}

The term Industry 4.0 (or 4th industrial revolution) is a technology-oriented concept concerning primarily the manufacturing domain, however, can be adapted and applied to any value chain organization [1]. The integration of Industry 4.0 principles in business processes, following Business Process Management (BPM) tools, could assist and facilitate their improvement [2]. BPM contribution to Industry 4.0 is accomplished using the method of Process Modeling, providing stakeholders with adequate means to control intelligent manufacturing processes and smart factories efficiently and effectively [3]. Business process models examine and exploit the behavioral aspects of a system and are usually developed in an early stage of requirements designing [1].

Model-based systems engineering (MBSE) is a key enabler for building complex systems as demonstrated by the increased number of related publications $[4,5]$. The deployment of employees as well as the human-machine interaction is depicted by systems models development [1, 6, 7] leading to a complete view of Industry 4.0 processes. Through the capability of process simulation via the configured models, a better understanding of systems operation could be achieved, providing feedback 
about changes and readjustments [8] which can be implemented for improved results and better resilience. Simulation as a method of modeling is proposed by [8], [9] and [10] as a reliable way of getting results. UML-based models are utilized by [1], [11], [12] and [13] while they constitute also a big category of process modeling techniques used as Business Process Management tool. Hence, both dynamic and static techniques are exploited for models and architectures configuration. BPMN, in which the architecture of this paper is based, is mentioned to be a valid and adaptable method for both static and dynamic approaches in modeling $[1,11]$.

Completed 5-level architectures are proposed by [14], [15] for the deployment of Industry 4.0 in manufacturing environment where real time data acquisition and management is needed for the operations control. According to [16] an architecture exploiting human knowledge for data input in smart factories can be developed. Vertical integration architecture is suggested by [17] in order to collect data and transform it into valuable information for the system. PERA (Purdue Enterprise Reference Architecture) for industry 4.0 is used by [18] as a base for adjusted architectures development such as this prosed in this study. The development of enterprise architecture provides business with useful details about how to align their strategy with their business processes in order to achieve the desirable results [19].

The aim of this paper is the development of a Business Process Modeling architecture prototype which is used to describe methodologies and guidelines for the design and combination of Business Processes and Industry 4.0 in an organization which is responsible for the middle and low pressure gas distribution networks operation and desires the transition of its processes to an Industry 4.0 framework. Initially, the views that will satisfy the needs of the organization are presented, followed by the description of the proposed architecture. PERA architecture was chosen as the base of the adjusted meta-architecture of this case, developed as a next-step emerging framework according to PERA principles, because of its simplicity and its generic nature [20] which facilitated the fitting with the needs and the mentality of the company. PERA and ARIS were combined for the development of a new meta-architecture based on the needs of a specific organization operating in the gas industry.

\section{Proposed Architecture}

The first step for the configuration of the proposed architecture is the understanding of the role of BPM in Industry 4.0 implementation in a gas company. As shown in Fig. 1, BPM constitutes the higher level (Level 6) of the "pyramid" which represents the vertical integration of Industry 4.0 in business processes, consisting of the level of modeling, execution and business process control. The lower level (Level 0) is constituted by the Actual Process of organization operation. Level 1 encompasses all the appropriate equipment for direct interaction and coordination with actual processes, followed by SCADA in Level 2 which collects the data of Level 1 equipment used in the actual processes. Level 3 includes Equipment System and Maintenance Management operating by the aggregation of the data come from SCADA. Level 4, Products Lifecycle Management (PLM), is the link between Level 3 and Level 5 because it 


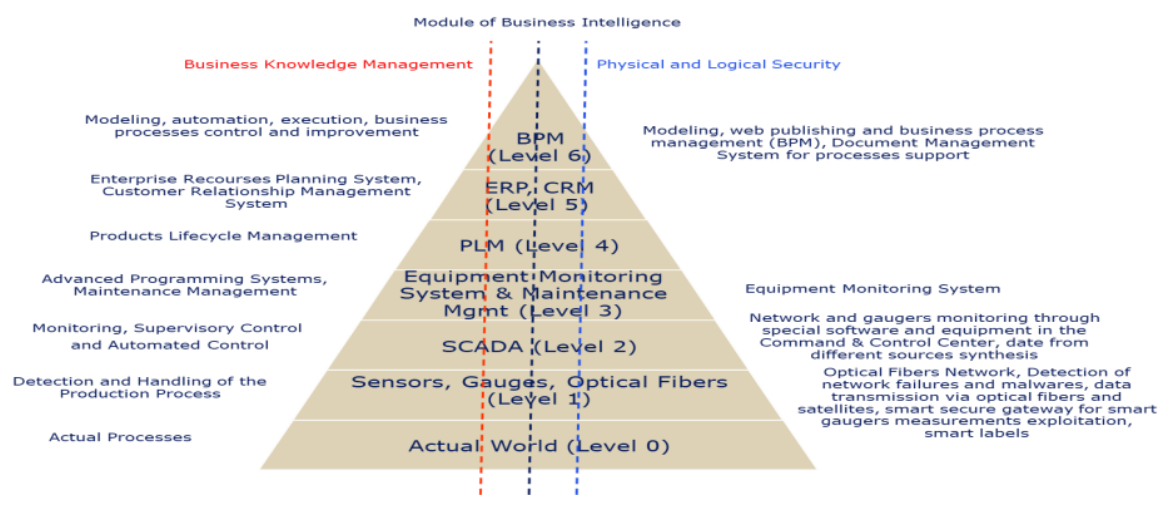

Fig. 1. The "pyramid" of Industry 4.0 implementation levels

develops products based on the requirements coming from the ERP and CRM systems of Level 5 and it simultaneously controls the low level production. The concept of security is vital in all levels of the architecture for a company operating gas distribution networks and has different expressions in the six levels of the pyramid. For example, security is important at a physical level (e.g., covering the risk of physical assets destruction) as well as at an informational and network level (e.g., preventing a cyber-attack). Similarly, knowledge has to be management in the different levels of the pyramid, in different ways (e.g. explicit knowledge concerning executional processes is expected to be found in the lower levels of the pyramid, possibly in the form of analytical procedures and work instructions, whereas more tacit knowledge is found in the higher levels, possibly in the form of management good practices and shared experiences).

Based on the needs of the organization in which the proposed architecture was implemented, the views of the system analysis have been detected and categorized as follows:

- Organization View: Encompasses the organizational structure of the company according to employees' positions and its allocation in departments.

- Process View: Composed of the processes, subprocesses and activities of the organization.

- Information Systems View: Depicts the information systems used by the company as well as the applications included in them and their interconnections

- Industry 4.0 and Internet of Things View: Analyzes the utilization of automations in the operations of semi-autonomous functions using sensors, actuators and telecommunication networks.

- Documents/Files View: The recording and categorization of significant documents and files for the business processes operation are included in this view.

- Rules/Legislation View: Refers to the business rules and laws which influence organization processes and should be noted down.

- Risks/Controls View: Includes risks listing according to their category and their implications in business processes. 
- Products/Services/Customers View: Contains the analysis of products and services provided by the examined organizations and the approaches on the basis of which its main customer categories are served, too.

In dependence to the views which are described and should be covered based on the analysis of the organization, ARIS was decided to be the modeling architecture and more specifically the meta-architecture modeling framework to be used. ARIS not only was selected because it completely encompasses the views which have to be included in the analysis, but it can be understandable and easily accessible by all the employees as well, owing to the existence of supporting software. In Fig. 2 the views of ARIS are presented, including the methods (diagrams) used in each view. ARIS views are: Organizational, Data, Processes, Functions and Products and Services. The representation is conducted through the House of ARIS depicting the interconnections between views. These views correspond to specific levels of the PERA architecture through specific modeling methods. In particular, in Levels $1,2 \& 3$ in which the Industry 4.0 principles are implemented in company processes, Network Diagrams, Network Topology Diagrams, IoT Object Definitions Diagrams, IoT Context Diagram and Information Carrier Diagrams are used. In order to represent the information systems requirements, structure and function in Levels 3, 4 \& 5, the Application System Type Diagrams, Application Collaboration Diagrams, Requirements Tree and Requirements Allocation Diagrams, Customer Journey Map and Customer Journey Landscape (for CRM), Product Service Tree and Information Carrier Diagram are used. BPM in Level 6 is expressed by Value-added Chain Diagram, Enterprise Collaboration Diagrams (BPMN), Function Allocation Diagrams (FAD), Business Rule Architecture Diagram, Business Controls Diagram KRI Allocation Diagrams, Risk Diagram and Information Carrier Diagram.

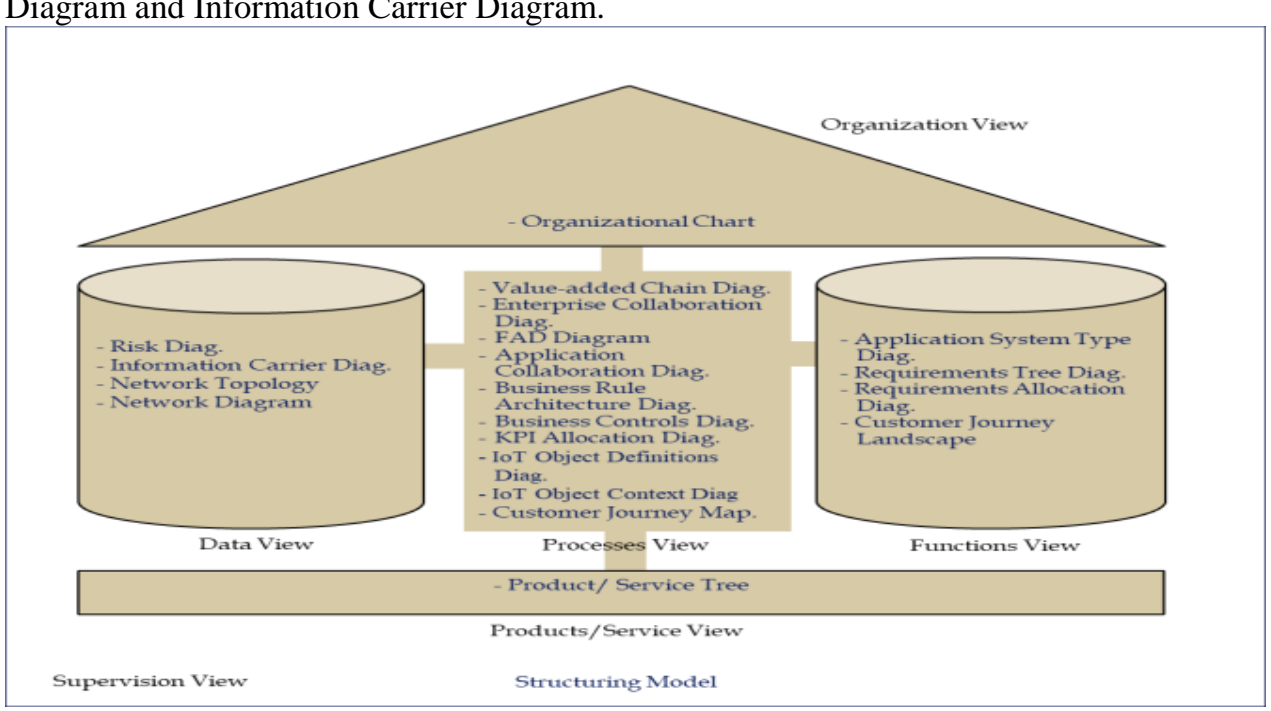

Fig. 2. Used diagrams distributed in ARIS view 
In Fig. 3 the methods of ARIS were redistributed to be adjusted in each view of organization. In both Fig. 2 and Fig. 3 an extra Supervision View has been added, constituting the common platform of connection between the other views, in the form of a control panel.

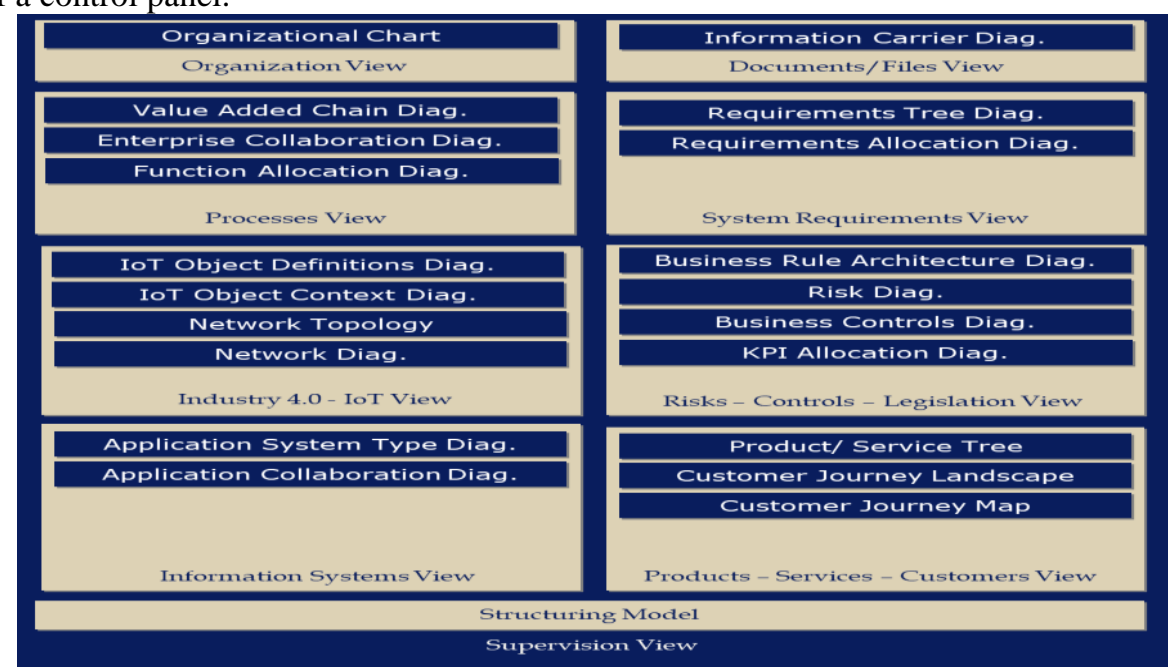

Fig. 3. Used Diagrams distributed in organization views

In particular, the Organization view is structured by the configuration of the Organizational Chart. The Information Carrier Diagram is used for the recording and categorization of documents and files covering the Documents/Files view. The Function view is supported by the Enterprise Collaboration Diagram which is the main diagram of the suggested architecture as it depicts all the functions of the organization in BPMN form and both "as-is" and "to-be" can be represented. BPMN diagrams are supported by Function Allocation Diagrams (FAD) which connect BPMN with the diagrams of the other views and Value Added Chain Diagrams which group the business processes in a high level.

The view of System Requirements is presented by the Requirements Tree Diagram determining the hierarchy of requirements which are subsequently analyzed by the Requirements Allocation Diagram. System requirements connect "as-is" with "to-be" diagrams and are connected with business process improvement initiatives.

One of the most important views for the utilization of the proposed metaarchitecture is the view of Industry 4.0 and IoT for the reason that it supports the transition of the organization in automations adoption. IoT Object Definition Diagram represents the structure of automations including the function of sensors and actuators supplemented by IoT Object Context Diagram which describes the function of the automation in a process. In addition, Network Topology and Network diagrams depict the communication and interconnection networks of the automations completing in that way the Industry 4.0 view in organization processes.

The view of Risks/Controls/Policies is analyzed as an integrated framework because of their correlation. Business Rule Architecture Diagram presents the business 
policies that the organization should comply with. Risk diagram lists the risk categories and the risks associated with the organization operation which are measured by the KPI Allocation Diagram and are confronted according to the recorded information encompassed in the Business Controls Diagram. The view of Information Systems is modeled through the Application System Type Diagram registering all the information systems used by the company and decomposing their structure and functionality through the Application Collaboration Diagram. The final view of Products/Services/Customers uses the Product/Service tree for the depiction of products and services offered by the organization to customers. Moreover, the route that is followed by the costumer from the beginning until the end of its touch with the company and the analysis of each step of the route parameters as well, are displayed by the Costumer Journey Landscape and the Costumer Journey Map, respectively.

In sum, the proposed architecture consists by the main view of Processes which constitutes its core, based on BPMN diagrams representing business processes, framed by the other views which supplement a completed framework harmonized with the needs of the studied gas company, in order to achieve the adoption of Industry 4.0 principles in its processes. BPMN lanes offer better interaction between physical and electronic actors, too. That was the reason for choosing BPMN as the central architecture diagram. The transition was primarily depended on the matching of Industry 4.0 and IoT methods in BPMN diagrams along with the cooperation with the methods of the other views. Fig. 4 represents an overview of the "connection of a new customer in the gas network", a core process of the company. In this process, the interaction of the actors is important to be shown in order to understand it better. A BPMN diagram can depict in high level of detail the interaction of the customer with the departments of the company and the external partners involved. Every activity of this process can be connected with other diagrams of other or the same view for better understanding of the system. For example, the smart tag activities in this process are associated with IoT Object Context Diagrams as a part of Industry 4.0 logic.

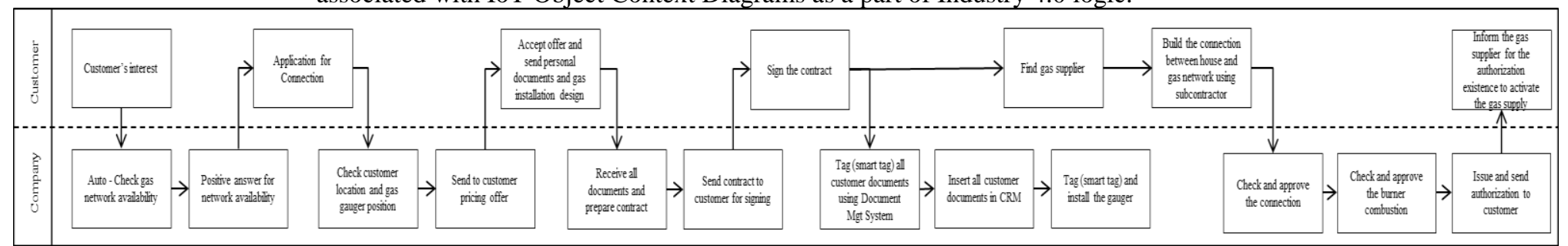

Fig. 4. (Simplified) Process of new customer connection in the gas network

\section{Conclusions \& Further Research}

Modeling of an enterprise system in the Industry 4.0 era is a complex task of strategic importance that faces many challenges in order to achieve the integration of different and often conflicting views in a holistic manner. In this paper, the design of an integrated architecture based on the ARIS framework is presented, incorporating 
the view of Industry 4.0 and Internet of Things. The architecture was developed for a company operating middle and low pressure gas distribution networks and was based on its strategic orientation and specific needs. It is understood that this is the starting point and many steps have to be taken in the future. The developed architecture has not been validated yet and has not been refined based on its full application. So far, 5 out of 108 identified business processes have been designed and 12 out of the 21 methods have been utilized from which only two involve cyber-physical operation, so the integration of all methods and their related and interconnected objects has not been fully verified. However, it has to be stated that the experience gained by now is encouraging, showing that the objective to connect the Industry 4.0 view with other organizational views in different management and operational levels is being fulfilled. The example of the (simplified) process of "new customer connection in gas network" shows the incorporation of Industry 4.0 workflows with other Business Processes as it is materialized through the developed architecture. After the refinement of the architecture in the case of the user company, it is interesting to test its applicability to other companies operating in the same or alternative sectors.

\section{Acknowledgements}

This research has been co-financed by the European Union and Greek national funds through the Operational Program Competitiveness, Entrepreneurship and Innovation, under the call RESEARCH - CREATE - INNOVATE (project code:T1EDK01825)

\section{References}

1. Petrasch, R. and Hentschke, R.: Process Modeling for Industry 4.0 Applications: Towards an Industry 4.0 Process Modeling Language and Method. In: 13th International Joint Conference on Computer Science and Software Engineering (JCSSE) on IEEE, Khon Kaen, Thailand (2016), [DOI: 10.1109/JCSSE.2016.7748885].

2. Nascimento, D.L., Alencastro, V., Gonçalves Quelhas, O.L., Gusmão Caiado, R.G., GarzaReyes, J.A. Lona, L.R. and Tortorella, G.: Exploring Industry 4.0 technologies to enable circular economy practices in a manufacturing context: A business model proposal. Journal of Manufacturing Technology Management, (2018), [DOI: 10.1108/JMTM-03-20180071].

3. Rehse, J.-R., Dadashnia, S. and Fettke, P.: Business process management for Industry 4.0 - Three application cases in the DFKI-Smart-Lego-Factory. it - Information Technology 60(3), 133-141 (2018)

4. Szvetits M. and Zdun U.: Systematic literature review of the objectives, techniques, kinds, and architectures of models at runtime. Software \& Systems Modeling, 15(1), pp. 31-69 (2016).

5. Heineck, T., Gonçalves, E., Sousa, A., Oliveira, M. and Castro, J.: Model-Driven Development in Robotics Domain: A Systematic Literature Review. In: Software Components, Architectures and Reuse (SBCARS), 2016 X Brazilian Symposium on IEEE, pp.151-160, Maringá-PR-Brazil (2016). 
6. Wortmann, A., Combemale, B. and Barais, O.: A Systematic Mapping Study on Modeling for Industry 4.0. In: 2017 ACM/IEEE 20th International Conference on Model Driven Engineering Languages and Systems (MODELS) on IEEE, Austin, TX, USA (2017).

7. Hermann, M., Pentek, T. and Otto, B.: Design principles for Industrie 4.0 scenarios In: 49th Hawaii International Conference on System Sciences (HICSS) on IEEE, Koloa, pp. 3928-3937. HI, USA (2016).

8. Uriarte, A.G., $\mathrm{Ng}$, A. and Moris, M.U.: Supporting the lean journey with simulation and optimazation in the context of Industry 4.0. Procedia Manufacturing 25, pp. 586-593 (2018).

9. Cicconi, P., Russo, A.C., Germani, M., Prist, M., Pallotta, E. and Monteri u, A.: CyberPhysical System Integration for Industry 4.0: Modelling and Simulation of an Induction Heating Process for Aluminium-Steel Molds in Footwear Soles Manufacturing. In: 2017 IEEE 3rd International Forum on Research and Technologies for Society and Industry (RTSI) on IEEE, Modena, Italy (2017).

10. Ullah, A.S.: Modeling and simulation of complex manufacturing phenomena using sensor signals from the perspective of Industry 4.0. Advanced Engineering Informatics 39, 1-13 (2019).

11. Petrasch, R. and Hentschke, R.: Towards an Internet-of-Things-aware Process Modeling Method - An Example for a House Suveillance System Process Model. In: 2nd Management and Innovation Technology International Conference (MITiCON2015), Bangkok, Thailand (2015).

12. Feldmann, S., Herzig, S.J.I., Kernschmidt, K., Wolfenstetter, T., Kammerl, D., Qamar, A., Lindemann, U., Krcmar, H., Paredis, C.J.J. and Vogel-Heuser, B.: Towards Effective Management of Inconsistencies in Model-Based Engineering of Automated Productions Systems. IFAC-Papers Online 48(3), 916-923 (2015).

13. Strang, D. and Anderl, R.: Assembly Process driven Component Data Model in CyberPhysical Production Systems. In: Proceedings of the World Congress on Engineering and Computer Science 2014 Vol II on IAENG, San Francisco, USA (2014).

14. Bagheri, B., Yang, S., Kao, H. and Lee, J.: Cyber-physical Systems Architecture for SelfAware Machines in Industry 4.0 Environment. IFAC-Papers Online 48(3), 1622-1627 (2015).

15. Lee, J., Bagheri, B. and Kao H.: A Cyber-Physical Systems architecture for Industry 4.0-based manufacturing systems. Manufacturing Letters 3, 18-23 (2015).

16. Fleischmann, H., Kohl, J. and Franke J.: A Reference Architecture for the Development of Socio-Cyber-Physical Condition Monitoring Systems. In: 2016 11th System of Systems Engineering Conference (SoSE) on IEEE, Kongsberg, Norway (2016).

17. Pérez, F., Irisarri, E., Orive, D., Marcos, M. and Estevez, E.: A CPPS Architecture approach for Industry 4.0. In: 2015 IEEE 20th Conference on Emerging Technologies \& Factory Automation (ETFA) on IEEE, Luxembourg, Luxembourg (2015).

18. Theorin, A., Bengtsson, K., Provost, J., Lieder, M., Johnsson, C., Lundholm, T. and Lennartson, B.: An event-driven manufacturing information system architecture for Industry 4.0. International Journal of Production Research 55(5), 1297-1311 (2017).

19. Kitstios, F. and Kamariotou, M.: Business strategy modelling based on enterprise architecture: a state of the art review. Business Process Management Journal (https://doi.org/10.1108/BPMJ-05-2017-0122).

20. Li, H. and Williams, T.J.: Some extensions to the Purdue Enterprise Reference Architecture (PERA): I. Explaining the Purdue architecture and the Purdue methodology using the axioms of engineering design. Computers in Industry, 34(3), 247-259 (1997). 